\title{
Modeling of Coupled Heat and Mass Transfers in a Stabilized Earthen Building Envelope with Thatched Fibers
}

\author{
Madeleine Nitcheu ${ }^{1,2, *}$, , Donatien Njomo ${ }^{1}$, Pierre Meukam ${ }^{3}$ and Cyrille Fotsing Talla ${ }^{1,4}$ (i) \\ 1 Environmental Energy Technologies Laboratory (EETL), Department of Physics, Faculty of Science, \\ University of Yaounde I, P.O. Box 812 Yaounde, Cameroon; dnjomo@usa.net (D.N.); \\ tallacyrille@yahoo.fr (C.F.T.) \\ 2 School of Geology and Mining Engineering, Department of Basic Scientific Teaching, \\ University of Ngaoundere, P.O. Box 454 Ngaoundere, Cameroon \\ 3 Laboratory of Energy, Water and Environment (L3E), National Advanced School of Engineering, Yaoundé, \\ P.O. Box 8390 Yaounde, Cameroon; pierre_meukam@yahoo.fr \\ 4 Department of Physics, Higher Teachers' Training College, University of Maroua, \\ P.O. Box 55 Maroua, Cameroon \\ * Correspondence: mnietzche2@gmail.com; Tel.: +237-694-060-245
}

Received: 10 August 2018; Accepted: 29 September 2018; Published: 2 October 2018 updates

\begin{abstract}
In order to reduce the heat and mass transfers in buildings, which increase energy bills, the development of composites materials such as earth bricks stabilized with thatch fibers is important for their construction. This paper aims to study a one-dimensional model of heat and moisture transfer through porous building materials. The coupled phenomena of heat and mass transfer are described by the Luikov model. Equations and boundary conditions are discretized using the finite difference method. The results obtained illustrate the temporal evolutions of the temperature and the moisture content, as well as the distributions of the temperature and moisture content inside the wall. The profile of the temperature and water content that are obtained are compared with the other numerical solutions that are available in the literature.
\end{abstract}

Keywords: heat and moisture transfer; thatch fibers; finite differences method

\section{Introduction}

Plant waste is valued in various ways in rural areas of Adamawa region in Cameroon. For instance, thatch fibers are used to cover the roofs because they offer good thermal insulation of the premises [1]. Concerning building envelopes, composite materials are used to improve the performance of simple brick. Meukam et al. [2] have shown that the incorporation of pozzolan or sawdust in laterite decreases the thermal conductivity and the density of the material, thus improving the thermal comfort in the habitat. Likewise, the addition of fibers in earth bricks varies their thermophysical properties [3]. The materials that are used as building envelopes are subjected to atmospheric conditions such as rain, wind, and solar radiation [4].There is a relationship between humidity, air, and heat transfer that impacts moisture accumulation in the wall. This influences the suitability of building materials in providing good thermal comfort [5-7]. These phenomena reveal a practical importance in the choice of materials for building construction. Sotehi et al. [8] have shown that fiber dosage influences mass transfer. For this reason, the dosage of thatched fibers in the materials shall be considered so that their hydrothermal properties can meet construction standards.

Several works have been done in order to track the evolution of moisture in buildings. To solve the equations governing this phenomenon, some authors use the analytical method $[6,7,9]$ 
while others prefer numerical solutions [8,10-12]. Philip and DeVries [12] developed a model explaining the movement of moisture in porous media under the influence of a temperature gradient. Tamene et al. [13] proposed a numerical model for heat and moisture diffusion through a wall exposed to solar heat flux, based on the finite difference method. As we intend to do, their study showed that it is possible to select and optimize the materials that make up the wall. Meukam [11] investigated a model of heat and mass transfers in a building envelope stabilized with earth bricks. He evaluated the temperature, relative humidity, and water content profiles in building envelopes made of the tested local materials. Therefore, it is therefore to study both heat and mass transfer through this kind of composite material.

The objective of our work is to study the evolution of heat and moisture in earth bricks stabilized with thatched fibers according to their dosage in this building material. After the discretization of the thermal and mass balance equations, a numerical code is developed and applied to four types of walls with different thatched fiber percentages. The spatial and temporal evolutions of the water content and the temperature within the material are studied, as well as the influence of the fiber dosage on transfers.

\section{Materials and Methods}

The materials used in this study consist of laterite mixed with thatch fibers. All of the samples have same dimensions: $10 \mathrm{~cm} \times 10 \mathrm{~cm} \times 3 \mathrm{~cm}$. The fiber content is $0 \%, 1 \%, 2 \%$, and $3 \%$ for $\mathrm{E}_{0}, \mathrm{E}_{1}, \mathrm{E}_{2}$, and $\mathrm{E}_{3}$ samples, respectively. Table 1 below presents the thermophysical properties of these composite materials.The measurements of thermophysical properties such as thermal conductivity and thermal diffusivity are obtained using the asymmetric hot plane method. It's a transient characterization approach that is used to get these properties [14]. In that study, the thermal conductivity of the composite material remains constant, starting from $4 \%$ of thatched fiber addition.

Table 1. Thermophysical properties of materials [14].

\begin{tabular}{cccc}
\hline Designation. & $\rho\left(\mathrm{kg} / \mathrm{m}^{3}\right)$ & $\lambda(\mathrm{J} / \mathrm{m} \cdot \mathrm{K}) \lambda(\mathrm{W} / \mathrm{mK})$ & $C_{\boldsymbol{P}}(\mathrm{J} / \mathbf{k g} \cdot \mathrm{K})$ \\
\hline $\mathrm{E}_{0}$ & 1775.86 & 0.710 & 870.46 \\
$\mathrm{E}_{1}$ & 1770.61 & 0.642 & 869.57 \\
$\mathrm{E}_{2}$ & 1751.91 & 0.549 & 867.18 \\
$\mathrm{E}_{3}$ & 1745.95 & 0.511 & 861.73 \\
\hline
\end{tabular}

\section{Formulation of the Problem}

The stabilized earth brick with thatched fibers that is used in this study as a building envelope is a porous material containing water in liquid or gaseous phase. The internal and external faces are at different temperatures. This results in conductive heat transfer through the material and heat transfer accompanying each phase change. The mathematical modeling of the thermomigration phenomenon that occurs within the material is done from a macroscopic approach that consists of introducing the experimental physical laws of the elementary processes in the heat mass conservation relations. The model that is applied to the materials is that of Philip [12]. It is based on the work of Luikov [15]. It predicts the distribution of temperature and water content in porous material. The mass balance and energy equations are given by the following expressions:

$$
\begin{aligned}
\rho_{0} C_{P} \frac{\partial T}{\partial t} & =\frac{\partial}{\partial x}\left(\lambda \frac{\partial T}{\partial x}\right)+\varepsilon L_{V} \rho_{0} \frac{\partial \theta}{\partial t} \\
\frac{\partial \theta}{\partial t} & =\nabla(D \nabla \theta+D \delta \nabla T)
\end{aligned}
$$

where $T$ represents the temperature, $x$ is the space variable, $\theta$ is the water content, $t$ is the time variable, $\rho_{0}$ is the material density, $C_{p}$ is the heat capacity, $\lambda$ is the thermal conductivity, $\varepsilon$ is the 
phase-change coefficient, $L_{v}$ is the latent heat of vaporization, $D$ is the moisture diffusivity, and $\delta$ is the thermomigration coefficient.

By rearranging Equations (1) and (2), we respectively obtain Equations (3) and (4):

$$
\begin{gathered}
\frac{\partial T}{\partial t}=\frac{\left(\lambda+\varepsilon L_{V} \rho_{0} D\right)}{\rho_{0} C_{p}} \frac{\partial^{2} T}{\partial x^{2}}+\frac{\varepsilon L_{V} D}{C_{p}} \frac{\partial^{2} \theta}{\partial x^{2}} \\
\frac{\partial \theta}{\partial t}=D \frac{\partial^{2} \theta}{\partial x^{2}}+D \delta \frac{\partial^{2} T}{\partial x^{2}} \\
\text { Let } D_{T}=\frac{\lambda+\varepsilon L_{v} \rho_{0} D}{\rho_{O} C_{p}} \text { and } D_{\theta}=\frac{\varepsilon L_{v} D}{C_{p}}
\end{gathered}
$$

We obtain the following Equations (5) and (6):

$$
\begin{aligned}
& \frac{\partial T}{\partial t}=D_{T} \frac{\partial^{2} T}{\partial x^{2}}+D_{\theta} \frac{\partial^{2} \theta}{\partial x^{2}} \\
& \frac{\partial \theta}{\partial t}=D \frac{\partial^{2} \theta}{\partial x^{2}}+D \delta \frac{\partial^{2} T}{\partial x^{2}}
\end{aligned}
$$

\subsection{Initial Conditions}

The initial temperature and moisture value in the building material are defined by Equation (7):

$$
T(x, 0)=T_{0} ; \theta(x, 0)=\theta_{0} \text { at }(t=0)
$$

\subsection{Boundary Conditions}

Outdoor conditions depend on several parameters such as rain, wind, or solar irradiation. The associated boundary conditions are illustrated in Figure 1.

For mass transfer:

$$
\begin{array}{ll}
x=0: & -\rho_{0} D \frac{\partial T}{\partial x}-\rho_{0} D \frac{\partial \theta}{\partial x}=h_{m 1}\left(\rho_{1}-\rho_{1 \infty}\right) \\
x=e: & -\rho_{0} D \frac{\partial T}{\partial x}-\rho_{0} D \frac{\partial \theta}{\partial x}=h_{m 2}\left(\rho_{2 \infty}-\rho_{2}\right)
\end{array}
$$

For heat transfer:

$$
\begin{aligned}
& x=0: \quad-\lambda \frac{\partial T}{\partial x}-\rho_{0} D \frac{\partial T}{\partial x}-\rho_{0} L_{V} D \frac{\partial \theta}{\partial x}=h_{1}\left(T_{f 1}-T(0)\right) \\
& x=e: \quad-\lambda \frac{\partial T}{\partial x}-\rho_{0} L_{V} D \frac{\partial T}{\partial x}-\rho_{0} L_{V} D \frac{\partial \theta}{\partial x}=h_{2}\left(T(e)-T_{f 2}\right) \\
& \underset{\text { Internal side }}{h_{1}}
\end{aligned}
$$

Figure 1. Physical model. 
The mass convection coefficients $h_{m 1}$ and $h_{m 2}$ are deduced from the thermal convection coefficients $h_{1}$ and $h_{2}$ by the Lewis relation giving by the following expression: $h_{m}=\frac{h_{c}}{\rho C_{p}}$ [16].

The mass densities $\rho_{1}, \rho_{1 \infty}, \rho_{2}$, and $\rho_{2 \infty}$ are determined from the following equations:

$$
\rho=\frac{P}{R_{h} T} \quad \text { with } \quad R_{h}=\frac{R_{s}}{1-\left(\theta \frac{P_{s a t}}{P}\right)\left(1-\frac{R_{s}}{R_{v}}\right)}
$$

$R_{s}=287.06 \mathrm{~J} / \mathrm{kg} \cdot \mathrm{K}$ is the universal gas constant of dry air, $R_{v}=461 \mathrm{~J} / \mathrm{kg} \cdot \mathrm{K}$ is the universal gas constant of water vapor, $P$ is the pressure, and $P_{\text {sat }}$ is the saturated vapor pressure.

The saturated vapor pressure $P_{\text {sat }}$ is determined by the Magnus formula [17]:

$$
P_{\text {sat }}=611.213 \times \exp \left(\frac{17.5043 T}{241.2+T}\right)
$$

We finally obtained:

$$
\rho(\theta, T, P)=\frac{1}{A}\left[P-\theta \times \exp \left(\frac{C T}{D+T}\right)\right]
$$

where $A=287.06 \times(T+273.15), B=230.617, C=17.5043$, and $D=241.2$.

\section{Numerical Resolution}

Applying a finite difference spatial discretization for the left-hand side of Equations (5) and (6), and the Crank-Nicolson method for the right-hand side of the same equations, we have:

$$
\begin{gathered}
\frac{T_{i}^{j+1}-T_{i}^{j}}{\Delta t}=\frac{D_{T}}{2 \Delta x^{2}}\left(\left(T_{i+1}^{j+1}-2 T_{i}^{j+1}+T_{i-1}^{j+1}\right)+\left(T_{i+1}^{j}-2 T_{i}^{j}+T_{i-1}^{j}\right)\right)+\frac{D_{\theta}}{2 \Delta x^{2}}\left(\left(\theta_{i+1}^{j+1}-2 \theta_{i}^{j+1}+\theta_{i-1}^{j+1}\right)+\left(\theta_{i+1}^{j}-2 \theta_{i}^{j}+\theta_{i-1}^{j}\right)\right) \\
\text { Hence, } \alpha=\frac{D_{T} \Delta t}{2 \Delta x^{2}} \text { and } \beta=\frac{D_{\theta} \Delta t}{2 \Delta x^{2}} \\
(1+2 \alpha) T_{i}^{j+1}-\alpha T_{i+1}^{j+1}-\alpha T_{i-1}^{j+1}-\beta \theta_{i+1}^{j+1}+2 \beta \theta_{i}^{j+1}-\beta \theta_{i-1}^{+1}=(1-2 \alpha) T_{i}^{j}+\alpha T_{i+1}^{j}+\alpha T_{i-1}^{j}+\beta \theta_{i+1}^{j}-2 \beta \theta_{i}^{j}+\beta \theta_{i-1}^{j} \\
\begin{array}{c}
\frac{\theta_{i}^{j+1}-\theta_{i}^{j}}{\Delta t}=\frac{D}{2 \Delta x^{2}}\left(\left(\theta_{i+1}^{j+1}-2 \theta_{i}^{j+1}+\theta_{i-1}^{j+1}\right)+\left(\theta_{i+1}^{j}-2 \theta_{i}^{j}+\theta_{i-1}^{j}\right)\right)+\frac{D \delta}{2 \Delta x^{2}}\left(\left(T_{i+1}^{j+1}-2 T_{i}^{j+1}+T_{i-1}^{j+1}\right)+\left(T_{i+1}^{j}-2 T_{i}^{j}+T_{i-1}^{j}\right)\right) \\
r=\frac{D \Delta t}{2 \Delta x^{2}} \text { and } b=\frac{D \delta \Delta t}{2 \Delta x^{2}} \\
(1+2 r) \theta_{i}^{j+1}-r \theta_{i+1}^{j+1}-r \theta_{i-1}^{j+1}-b T_{i+1}^{j+1}+2 b T_{i}^{j+1}-b T_{i-1}^{j+1}=(1-2 r) \theta_{i}^{j}+r \theta_{i+1}^{j}+r \theta_{i-1}^{j}+b T_{i+1}^{j}-2 b T_{i}^{j}+b T_{i-1}^{j}
\end{array}
\end{gathered}
$$

The discretization of the boundary conditions is given by relations (19)-(22).

For mass transfer, we have:

$$
\begin{aligned}
& (x=0):-\frac{\left(T_{i+1}^{j}-T_{i}^{j}\right)}{\Delta x}-\frac{\left(\theta_{i+1}^{j}-\theta_{i}^{j}\right)}{\Delta x} \frac{h_{m 1}}{\rho_{0} D}\left(\rho_{1}-\rho_{1 \infty}\right) \\
& (x=e):-\frac{\left(T_{i}^{j}-T_{i-1}^{j}\right)}{\Delta x}-\frac{\left(\theta_{i}^{j}-\theta_{i-1}^{j}\right)}{\Delta x} \frac{h_{m 2}}{\rho_{0} D}\left(\rho_{2 \infty}-\rho_{2}\right)
\end{aligned}
$$

For heat transfer:

$$
\begin{aligned}
& (x=0):-\left(\lambda+\rho_{0} D\right) \frac{\left(T_{i+1}^{j}-T_{i}^{j}\right)}{\Delta x}-\rho_{O} L_{v} D \frac{\left(\theta_{i+1}^{j}-\theta_{i}^{j}\right)}{\Delta x}=h_{1}\left(T_{f 1}-T(0)\right) \\
& (x=e):-\left(\lambda+\rho_{0} D\right) \frac{\left(T_{i}^{j}-T_{i-1}^{j}\right)}{\Delta x}-\rho_{O} L_{v} D \frac{\left(\theta_{i}^{j}-\theta_{i-1}^{j}\right)}{\Delta x}=h_{2}\left(T(e)-T_{f 2}\right)
\end{aligned}
$$

The numerical resolution of the coupled system with the initial condition and the boundary conditions passes through a discretization according to the implicit scheme of Crank-Nicolson [18] 
leading to two algebraic systems, one having an unknown temperature and the other having the water content.

\section{Results and Discussions}

The results presented in this work relate to the study of coupled heat and moisture transfers that occur within four wall types $\left(\mathrm{E}_{0}, \mathrm{E}_{1}, \mathrm{E}_{2}\right.$, and $\left.\mathrm{E}_{3}\right)$ of 3-cm thickness. In the initial state, the walls have a constant temperature of $T_{0}=20{ }^{\circ} \mathrm{C}$ and an initial water content of $\theta_{0}=0.2 \mathrm{~kg} / \mathrm{kg}$ [4]. The mass diffusivity coefficients are derived from Tamene et al. [13] as well as the values of the boundary conditions, which are: $h_{1}=50 \mathrm{~W} / \mathrm{m}^{2} \cdot \mathrm{K}, h_{2}=100 \mathrm{~W} / \mathrm{m}^{2} \cdot \mathrm{K} T_{f 1}=15^{\circ} \mathrm{C}, \theta_{1 \infty}=0.5 \mathrm{~kg} / \mathrm{kg}$, and $\theta_{2 \infty}=0.75 \mathrm{~kg} / \mathrm{kg}$.

Figures 2 and 3 represent the evolution of the temperature and the water content respectively as a function of time at the position $x=1.2 \mathrm{~cm} x=1.2 \mathrm{~cm}$. The shape of these curves corresponds to those obtained by Hens, Remache et al. and Chikhi $[7,19,20]$. Figure 2 shows that in the time interval $(0<t<120 \mathrm{~min})$, there is a rapid rise in the average temperature of the wall, which causes evaporation.

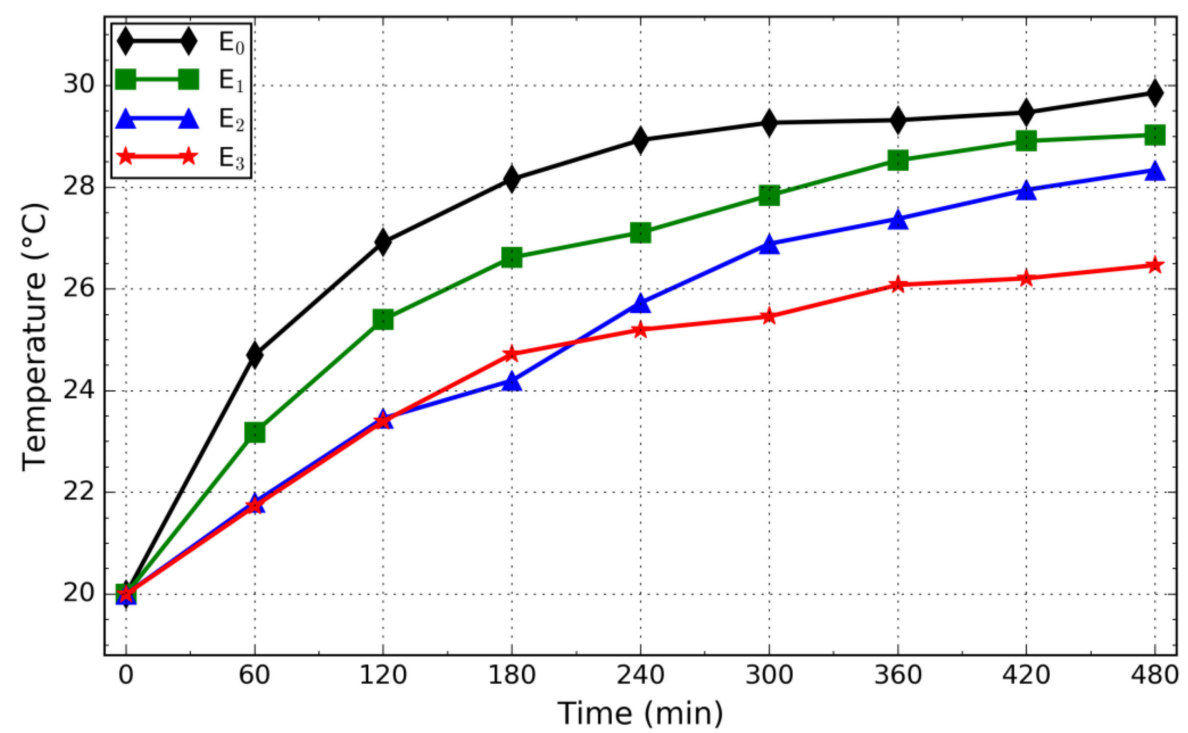

Figure 2. Influence of thatched fibers percentage on the temperature profile at $x=1.2 \mathrm{~cm}$.

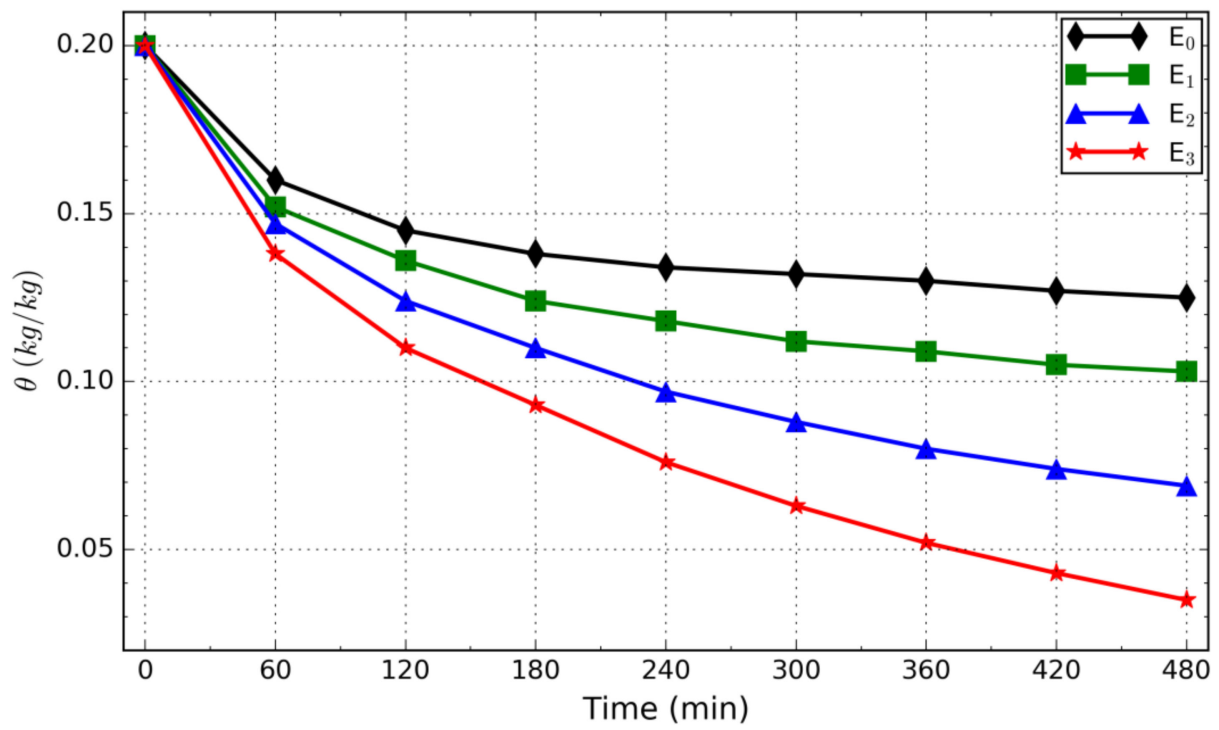

Figure 3. Influence of the thatched fibers percentage on the water content profile at $x=1.2 \mathrm{~cm}$. 
This happens only on the surface, and it results in a linear decrease of the average water content (see Figure 3). During this period, the mass transfer can generally be assimilated to the evaporation at the free surface of a liquid [8]. This continues until the capillary forces that bring the moisture in liquid form from the inside of the wall toward the outer surface become rather weak, which indicates that the liquid phase is discontinuous and no longer flows [8].

As a result, the transfer of moisture in the liquid phase to the surface stops. However, an evaporation front appears and propagates toward the inside of the wall. Beyond $120 \mathrm{~min}$, we notice that the average rate of humidity drops considerably; it becomes very low, and the temperature of the wall becomes almost constant.

These curves also show the influence of the dosage of thatch fibers on the temperature and humidity profiles. We see in Figure 3 that all of the curves have the same shape. It is observed that for a given moment, the temperature decreases as the fiber dosage increases. This can be justified by the composite materials having a low thermal conductivity and therefore being considered thermally insulating materials.

Moreover, the increase in the quantity of fibers that are introduced into the earth brick modifies the profile of the water content, as shown in Figure 3. This modification of the slope can be explained by the lightness of these composite materials. The phenomenon of dispersion within the material significantly increases the opening of the pores, which favors the elimination of water. In addition, it can be seen that between 0-120min, the curves corresponding to the samples $E_{2}$ and $E_{3}$ are merged, and beyond this range they diverge.

Figures 4 and 5 showed the spatial distributions of temperature and moisture content throughout the wall for a period of time that is equal to $60 \mathrm{~min}(t=60 \mathrm{~min})$ for the composites materials $\mathrm{E}_{0}, \mathrm{E}_{1}, \mathrm{E}_{2}$, and $E_{3}$. It can be noticed that the temperature in the wall increases in the space through the addition of thatched fibers (Figure 4). This is due to the ambient temperature, which is higher than the wall's temperature. It can be noticed that in Figure 5, the moisture content in the wall reduces in the space with the addition of thatched fibers. The reduction rate of the moisture content is higher in the surface region compared to the interior of the wall; moreover, at first, the moisture content reduces rapidly, and as the heating period progresses, the rate of reduction of the moisture content becomes less.

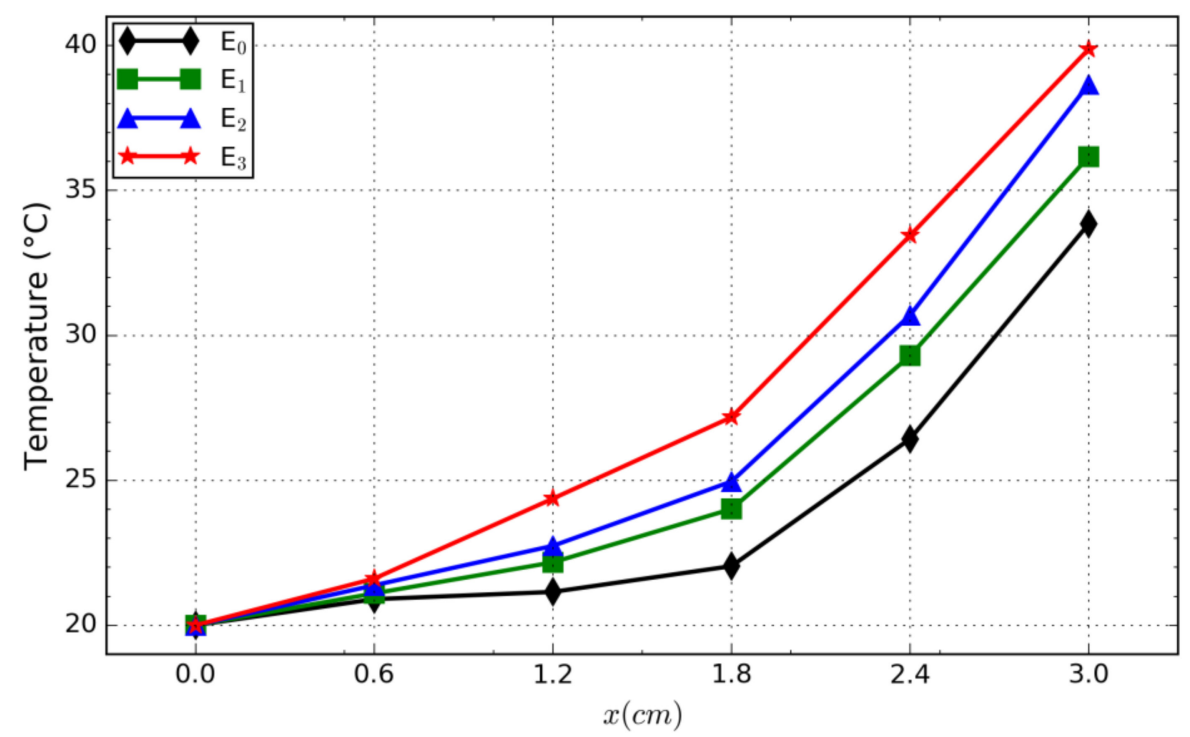

Figure 4. Influence of the thatched fibers percentage on the temperature profile through the composite material at $t=60 \mathrm{~min}$. 


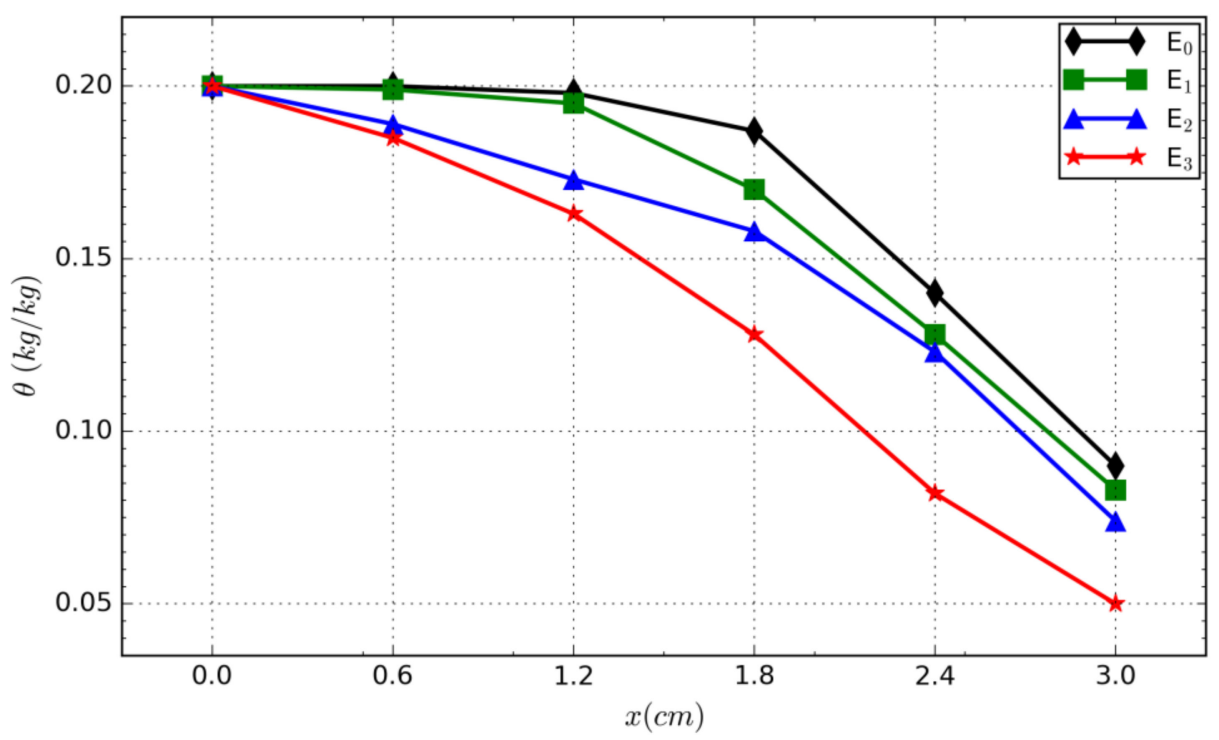

Figure 5. Influence of the thatched fibers percentage on the water content profile through the composite material at $t=60 \mathrm{~min}$.

\section{Conclusions}

In this paper, we carried out numerical simulations to study the coupled heat and mass transfers across wall of a building envelope that is subjected to two different atmospheric conditions. The envelopes that were studied consist of either simple earth bricks or composite materials (laterite and thatch fiber). The resulting equations were discretized using the finite difference method. All of the results that were obtained make it possible to highlight the evolutions of the temperature and the water content. It is clear that the addition of thatched fibers in the laterite soil makes the material hygroscopic and more thermally insulating. The results that are obtained are in agreement with those found in the literature.

Author Contributions: Conceptualization, D.N. and P.M.; Formal analysis, D.N. and P.M.; Methodology, M.N.; Writing manuscript, M.N. and C.F.T.

Funding: This research received no external funding.

Acknowledgments: The authors would like to thank the Local Materials Promotion Authority (MIPROMALO) in Cameroon which helps in conditioning and in the mechanical characterization of the samples used for this study and the laboratory of Energy, Water and Environment (L3E), National Advanced School of Engineering which helped in their thermo-physical characterization. We are also grateful to Eric Kabe Moukete for his computing assistance.

Conflicts of Interest: The authors declare no conflict of interest.

\section{Nomenclature}

$C_{P} \quad$ Specific heat $(\mathrm{J} / \mathrm{kg} . \mathrm{K})$

$D \quad$ Moisture diffusivity $\left(\mathbf{m}^{2} / \mathbf{s}\right)$

$h \quad$ Heat convection transfer coefficient $\left(\mathbf{W} / \mathbf{m}^{2} \cdot \mathbf{K}\right)$

$h_{m} \quad$ Mass convection transfer coefficient $(\mathbf{m} / \mathbf{s})$

e Wall tchikness (m)

$L_{V} \quad$ Latent heat of vaporisation $(\mathrm{J} / \mathbf{k g})$

$P \quad$ Pressure $(\mathrm{Pa})$

$T$ Temperature $\left({ }^{\circ} \mathrm{C}\right)$

$t \quad$ Time (s) 


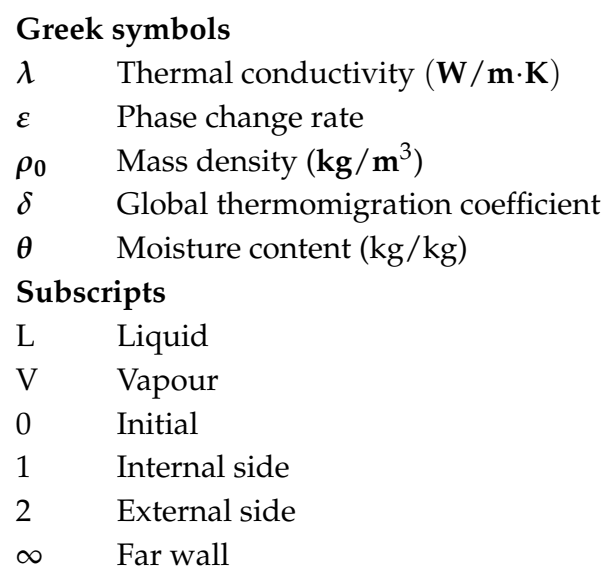

\section{References}

1. Beguin, J.B.; Kalt, M.; Leroy, J.L.; Louis, D.; Makary, J.; Pelloux, P.; Peronne, H.N. L'habitat au Cameroun; Paris-VII ${ }^{\mathrm{e}}$, Editions de l'Union Française; Publication de l'office de la recherche scientifique Outre-Mer: Paris, France, 1952.

2. Meukam, P.; Noumowe, A.; Kofane, T.C. Thermo Physical Properties of Lateritic Soil Bricks: Influence of Water Content; International Atomic Energy Agency (IAEA): Vienna, Austria, 2002; Volume 34, p. 22, IC/2002/157. Available online: https://inis.iaea.org/collection/NCLCollectionStore/_Public/34/035/ 34035601.pdf (accessed on 10 August 2018).

3. Petkova-Slipets, R.; Zlateva, P. A thermal insulating properties of straw filled environmentally friendly building materials. Civ. Environ. Eng. 2017, 13, 52-57. [CrossRef]

4. Janssen, H.; Blocken, B.; Carmeliet, J. Conservative modelling of the moisture and heat transfer in building components under atmospheric excitation. Int. J. Heat Mass Transf. 2007, 50, 1128-1140. [CrossRef]

5. Qin, M.; Belarbi, R.; Aït-Mokhtar, A. Transfer function method to calculate simultaneous heat and moisture transfer in porous building materials. In Proceedings of the Annex 41 MOIST-ENG, Working Meeting, Kyoto, Japan, 3-5 April 2006.

6. Djongyang, N.; Tchinda, R.; Njomo, D. A study of coupled heat and mass transfer across a porous building component in intertropical conditions. Energy Build. 2009, 41, 461-469. [CrossRef]

7. Hens, H.L.S.C. Combined heat, air, moisture modelling: A look back, how, of help? Build. Environ. 2015, 91, 138-151. [CrossRef]

8. Sotehi, N.; Chaker, A. Numerical analysis of simultaneous heat and mass transfer in cork lightweight concretes used in building envelopes. Phys. Procedia 2014, 55, 429-436. [CrossRef]

9. Chang, W.J.; Weng, C.-I. An analytical solution to coupled heat and moisture diffusion transfer in porous materials. Int. J. Heat Mass Transf. 2000, 43, 3621-3632. [CrossRef]

10. Liua, F.; Jia, B.; Chena, B.; Geng, W. Moisture transfer in building envelope and influence on heat transfer. Procedia Eng. 2017, 205, 3654-3661. [CrossRef]

11. Meukam, P. Modeling of Heat and Mass Transfer in Lateritic Building Envelopes; IC/2002/157; International Atomic Energy Agency (IAEA): Vienna, Austria, 2004; Volume 34, p. 22, IC/2004/111. Available online: http:/ / www.ictp.it/ pub_off (accessed on 10 August 2018).

12. Philip, J.R.; De Vries, D.A. Moisture movement in porous media under temperature gradients. Trans. Am. Geophys. Union 1957, 38, 222-232. [CrossRef]

13. Tamene, Y.; Abboudi, S.; Bougriou, C. Study of heat and moisture diffusion through a wall exposed to solar heat flux. J. Eng. Sci. Technol. 2011, 6, 429-444.

14. Nitcheu, M.; Meukam, P.; Damfeu, J.C.; Njomo, D. Thermomechanical characterization of compressed clay bricks reinforced by thatch fibres for the optimal use in building. Mater. Sci. Appl. 2018. submitted.

15. Luikov, A.V. Heat and Mass Transfer in Capillary-Porous Bodies; Chap 6; Pergamon Press: Oxford, UK, 1966; pp. 1-531. 
16. Belarbi, N.; Saighi, M. Etude Comparative des Méthodes D'évaluation du Taux D'évaporation à Partir d'une Surface D'eau Libre: Application Aux Régions Arides et semi Arides en Algérie, 13èmes Journées Internationales de Thermique; ENStimac: Albi, France, 2007.

17. World Meteorological Organization. Guide to Meteorological Instruments and Methods of Observation, annex4-B? Formulae for the Computation of Measures of Humidity; World Meteorological Organization: Geneva, Switzerland, 2008.

18. Gerald, C.F.; Wheatley, P.O. Applied Numerical Analysis, 7th ed.; Addison Wesley Publishing Company: Boston, MA, USA, 1978.

19. Remache, L.; Belhamri, A. Modélisation du séchage par convection. Revue des Energies Renouvelables CISM'08 Oum El Bouaghi. Available online: https://www.cder.dz/download/CISM08_26.pdf (accessed on 10 August 2018).

20. Chikhi, A. Etude du Comportement Thermo-Hydrique des Parois des Bâtiments. Influence des Effets de L'état Hygrothermique et des Propriétés Thermo-Physiques. Ph.D. Thesis, Université Constantine, Constantine, Algeria, 2006; pp. 1-157.

(C) 2018 by the authors. Licensee MDPI, Basel, Switzerland. This article is an open access article distributed under the terms and conditions of the Creative Commons Attribution (CC BY) license (http:/ / creativecommons.org/licenses/by/4.0/). 